\title{
Molecular mechanisms of congenital hyperinsulinism
}

\author{
Sofia A Rahman ${ }^{1, *}$, Azizun Nessa ${ }^{1, *}$ and Khalid Hussain ${ }^{1,2}$ \\ ${ }^{1}$ Genetics and Genomic Medicine, UCL Institute of Child Health, 30 Guilford Street, London WC1N 1EH, UK \\ ${ }^{2}$ Department of Paediatric Endocrinology, Great Ormond Street Hospital for Children NHS, 30 Guilford Street, \\ London WC1N 1EH, UK \\ *(S A Rahman and A Nessa contributed equally to this work)
}

Correspondence

should be addressed

to $K$ Hussain

Email

Khalid.Hussain@ucl.ac.uk

\begin{abstract}
Congenital hyperinsulinism $(\mathrm{CHI})$ is a complex heterogeneous condition in which insulin secretion from pancreatic $\beta$-cells is unregulated and inappropriate for the level of blood glucose. The inappropriate insulin secretion drives glucose into the insulin-sensitive tissues, such as the muscle, liver and adipose tissue, leading to severe hyperinsulinaemic hypoglycaemia $(\mathrm{HH})$. At a molecular level, genetic abnormalities in nine different genes $(A B C C 8$, KCNJ11, GLUD1, GCK, HNF4A, HNF1A, SLC16A1, UCP2 and HADH) have been identified which cause $\mathrm{CHI}$. Autosomal recessive and dominant mutations in $A B C C 8 / K C N J 11$ are the commonest cause of medically unresponsive $\mathrm{CHI}$. Mutations in GLUD1 and $H A D H$ lead to leucine-induced $\mathrm{HH}$, and these two genes encode the key enzymes glutamate dehydrogenase and short chain 3-hydroxyacyl-CoA dehydrogenase which play a key role in amino acid and fatty acid regulation of insulin secretion respectively. Genetic abnormalities in HNF4A and HNF1A lead to a dual phenotype of $\mathrm{HH}$ in the newborn period and maturity onset-diabetes later in life. This state of the art review provides an update on the molecular basis of $\mathrm{CHI}$.
\end{abstract}

Key Words
glucose
- insulin
congenital hyperinsulinism
- hypoglycaemia
- KATP channels
- genetics
- human
- development

Journal of Molecular Endocrinology (2015) 54, R119-R129

\section{Introduction}

Congenital hyperinsulinism (CHI) refers to a group of disorders characterised by dysregulated insulin secretion from pancreatic $\beta$-cells. As insulin is the key hormone involved in the regulation of the blood glucose level, its inappropriate release leads to persistent hyperinsulinaemic hypoglycaemia $(\mathrm{HH})$. This drives glucose into the insulin sensitive tissues and simultaneously suppresses lipolysis and ketogenesis. The combined hypoketonaemic and hypoglycaemic characteristic of $\mathrm{CHI}$ increases the risk of brain injury in infants and children with this disorder (Aynsley-Green et al. 2000).

CHI typically presents in the newborn period with symptoms of hypoglycaemia, with most cases being sporadic; however, late-onset presentations of $\mathrm{CHI}$ can also occur. The general CHI prevalence is 1:50 000 births increasing to 1:2500 in consanguineous families (Bruining 1990).
The molecular basis of CHI involves defects in key genes that control the complex mechanisms of insulin secretion in the pancreatic $\beta$-cell. Insulin secretion is controlled to keep the fasting blood glucose level between 3.5 and $5.5 \mathrm{mmol} / \mathrm{l}$. Genetic mechanisms that perturb this precise control lead to $\mathrm{HH}$. This review discusses the current knowledge of the molecular mechanisms that lead to unregulated insulin secretion.

\section{Normal physiological mechanisms of insulin secretion}

Insulin secretion from pancreatic $\beta$-cells is primarily regulated by glucose metabolism. Post-prandial glucose enters the $\beta$-cells via the non-insulin-dependent glucose transporter type 2 (GLUT2). Glucose is then metabolised

Published by Bioscientifica Ltd 
via glycolysis and tricarboxylic acid (TCA) cycles and yields the high-energy molecule, ATP. Pancreatic $\beta$-cells control insulin release by two major pathways; by means of the ATP-sensitive potassium channels $\left(\mathrm{K}_{\mathrm{ATP}}\right)$ and by $\mathrm{K}_{\mathrm{ATP}}$-channel-independent means.

The $\mathrm{K}_{\mathrm{ATP}}$-dependent control of insulin release is dependent on changes in the ratio of ATP:ADP leading to closure of potassium channels and promotes membrane depolarisation. This triggers voltage-gated calcium channels to open causing an influx of extracellular calcium, which leads to exocytosis of insulin-containing granules. On the other hand $\mathrm{K}_{\mathrm{ATP}}$-independent pathways involves the augmentation of insulin secretion by increasing cytosolic $\mathrm{Ca}^{2+}$ concentration and the recruitment of both $\beta$-cell protein kinases $\mathrm{A}$ and $\mathrm{C}$ to promote insulin exocytosis (Gembal et al. 1992, Komatsu et al. 1995).

In this review, we discuss the molecular mechanisms of $\mathrm{CHI}$ that have given valuable insights into $\beta$-cell physiology and have aided in patient care and management. We outline the genetic basis of $\mathrm{CHI}$ and crucial studies that have been pivotal in understanding this complex and rare disease.

\section{Molecular genetics of $\mathrm{CHI}$}

So far, abnormalities in nine genes have been implicated in CHI; these are classified into two categories namely: 'channelopathies' and 'metabolopathies' (Dunne et al. 2004). The former is attributed to the $\mathrm{K}_{\mathrm{ATP}}$ channel genes (ABCC 8 and KCNJ11) and latter to genes regulating different metabolic pathways (GLUD1, glucokinase (GCK), hepatocyte nuclear factor 4 homeobox A (HNF4A), HNF1A, SLC16A1, uncoupling protein 2 (UCP2) and $H A D H$ ) (Table 1). The most common disorders are those affecting the $K_{\text {ATP }}$ channel genes and these are predominantly recessive mutations. The other seven genes are less common causes of $\mathrm{CHI}$, but are dominant mutations.

Table 1 Incidence of $\mathrm{CHI}$ due to known genetic mutations

\begin{tabular}{|c|c|c|}
\hline Gene & $\begin{array}{l}\text { Number of } \mathrm{CHI} \text { cases } \\
\text { due to this gene (\%) }\end{array}$ & References \\
\hline$A B C C 8 / K C N J 11$ & 36.3 & Kapoor et al. (2013) \\
\hline GLUD1 & 5.9 & Flanagan et al. (2010) \\
\hline$H A D H$ & 1 & Kapoor et al. (2013) \\
\hline GCK & $<1$ & Glaser et al. (1998) \\
\hline SLC16A1 & $<1$ & Otonkoski et al. (2003) \\
\hline HNF4A & 5 & Flanagan et al. (2010) \\
\hline HNF1A & $\ll 1$ & Snider et al. (2013) \\
\hline UCP2 & $\ll 1$ & $\begin{array}{l}\text { Gonzalez-Barroso } \\
\text { et al. (2008) }\end{array}$ \\
\hline
\end{tabular}

\section{Channelopathies}

The $\boldsymbol{A B C C 8}$ gene: $\mathbf{K}_{\mathbf{A T P}}-\mathbf{C H I}$ The $A B C C 8$ gene is found on chromosome 11p15.1, and contains 39 exons (Inagaki et al. 1995). This encodes the sulfonylurea receptor 1 (SUR1) protein or an alternative spliced variant. SUR1 is a member of the ATP-binding cassette transporters, which promote ATP hydrolysis to transport substrates. However, SUR1 does not directly transport substrates, instead it regulates the activity of Kir6.2 in the $\mathrm{K}_{\mathrm{ATP}}$ channel complex. A single SUR1 subunit is composed of three transmembrane domains (TMD0, TMD1 and TMD2) containing 17 transmembrane helices, two cytosolic nucleotide-binding domains (NBD1 and NBD2) and a cytosolic linker (L0) (Fig. 1).

The KCNJ11 gene: $\mathbf{K}_{\mathbf{A T P}}-\mathbf{C H I}$ Like $A B C C 8$, the KCNJ11 gene is also located on chromosome 11p15.1, containing a single exon. This encodes Kir6.2, a 390 amino acid protein (Inagaki et al. 1995). It is originally from a superfamily that is further divided into seven subfamilies ranging from Kir1 to Kir7. Kir6.2 is an unconventional pore-forming subunit of $\mathrm{K}_{\mathrm{ATP}}$ channels which acts as a bio-diode in the cell surface. Kir proteins favour passing positive currents 'inward', even when the potassium $\left(\mathrm{K}^{+}\right)$ concentration is equal on both sides of the membrane, and hence is termed an 'inward rectifier'. Kir6.2 is a 'weak' inward rectifier unlike classic Kir channels (Doupnik et al. 1995). A single Kir6.2 subunit contains two putative TMDs, linked by an extracellular pore-forming region and cytoplasmic - $\mathrm{NH} 2$ and - $\mathrm{COOH}$ terminal domains. Within the $\mathrm{K}_{\mathrm{ATP}}$ channel complex, the Kir6.2 subunit forms a tetrameric complex, harbouring the inhibitory binding site (Saint-Martin et al. 2011).

$\mathbf{K}_{\mathbf{A T P}}-\mathbf{C H I}$ Recessive inactivating mutations in the $A B C C 8$ and KCNJ11 genes are the most common cause of CHI. To date, 150 types of mutations in ABCC 8 and 24 in KCNJ11 have been identified (Flanagan et al. 2009 ), these account for approximately $36.3 \%$ of all $\mathrm{CHI}$ cases (Kapoor et al. 2013). Mutations in ABCC8 or KCNJ11 can affect the functioning of $\mathrm{K}_{\mathrm{ATP}}$ channels by either affecting the surface expression or impairing the ability of MgADP to stimulate channel activity (Nichols et al. 1996). In either case, there is continuous depolarisation of the pancreatic $\beta$-cell membrane which leads to unregulated insulin secretion.

Class 1 mutations in $A B C C 8$ or KCNJ11 lead to proteins which fail to reach the plasma membrane due to the impaired synthesis or maturation of SUR1.

Published by Bioscientifica Ltd. 
A Sulfonylurea receptor type 1 (SUR1)

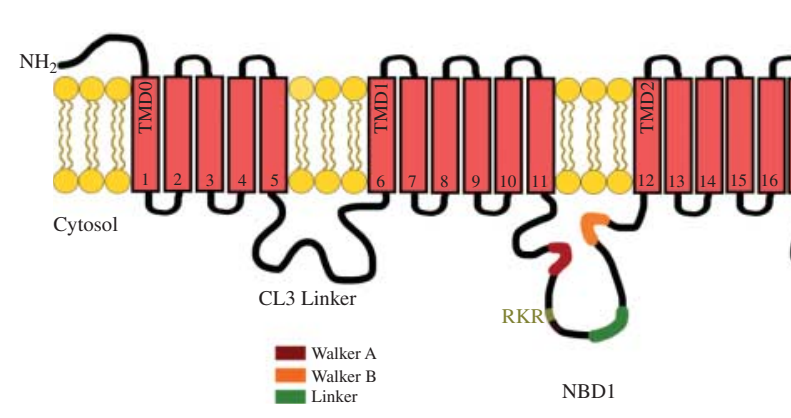

Inward rectifier $\left(\mathrm{K}_{\mathrm{ir}} 6.2\right)$ pore-forming subunit

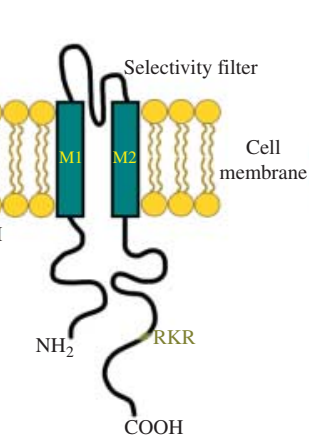

B

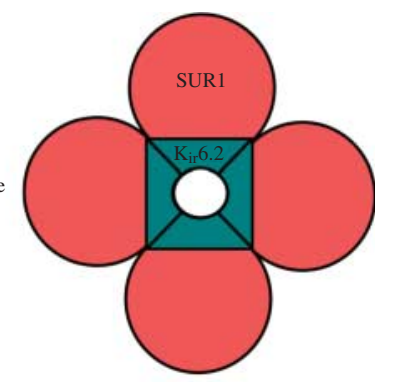

Figure 1

Image of $\mathrm{K}_{\text {ATP }}$ channel structure in the cell membrane. (A) SUR1 is the regulatory subunit composed of three TMDs (TMD0, TMD1 and TMD2), each with five to six transmembrane helices. There are two cytosolic nucleotide-binding domains (NBD1 and NBD2), and the conserved sequences include the Walker $A$ and Walker $B$ motifs. The linker regions are located between the Walker A and B motifs. Kir6.2 is the pore-forming subunit. It is a tetrameric complex made up of four proteins, each with two

Alternatively, class 1 mutations can also lead to defective trafficking of SUR1 and as Kir6.2 expression is dependent on SUR1 surface expression, Kir6.2 is also absent from the membrane (Saint-Martin et al. 2011). Whereas, class 2 mutations produce $\mathrm{K}_{\mathrm{ATP}}$ channel complexes which are present in the cell membrane but are non-functional. These defective $K_{\text {ATP }}$ channels are insensitive to the changing concentrations of MgADP, hence they remain closed even when the glucose levels are low (Saint-Martin et al. 2011).

Recessive $\boldsymbol{A B C C 8 / K C N J 1 1}$ mutations The molecular mechanisms of recessive $A B C C 8$ or $K C N J 11$ disease causing mutations have been described in the literature over the past 18 years. The molecular basis involves the following mechanisms:

Defects in biogenesis and turnover Results of pulse labelling studies have been used to identify individual SUR1 expression with a half-life of $25.5 \mathrm{~h}$, whereas Kir6.2 has a shorter half-life of just $36 \mathrm{~min}$. However, when the two subunits are co-expressed, Kir6.2 degradation is eliminated. The ABCC8 F1388del mutation and the KCNJ11 W91R mutation are two examples of mutations resulting in subunits that associate, but then dissociate freely and degrade rapidly, affecting biogenesis and turnover of $\mathrm{K}_{\mathrm{ATP}}$ channels (Crane \& Aguilar-Bryan 2004).

Defects in channel trafficking The correct formation of $\mathrm{K}_{\mathrm{ATP}}$ channels in the endoplasmic reticulum (ER) requires the shielding of the ER retention signal (RKR) (Arg-Lys-Arg) putative membrane-spanning domains, which are linked by an extracellular pore-forming region and cytoplasmic $-\mathrm{NH} 2$ and $-\mathrm{COOH}$ terminal domains. Both SUR1 and Kir6.2 contain the RKR sequence which is the endoplasmic reticulum retention signal. (B) Illustration of the predicted octameric structure of $\mathrm{K}_{\text {ATP }}$ channels. It is made up of four Kir6.2 proteins in the centre forming the pore, each with an associated SUR1 protein.

and enables the protein complex to exit the ER. The RKR is present in the C-terminal region of Kir6.2 and N-terminal side of NBD2 in SUR1. Hence the last 36 amino acid residues of Kir6.2 are highly significant as they contain the RKR signal peptide. Removal of these amino acids results in the surface expression of homotetrameric Kir6.2 in the absence of the SUR1 proteins (Tucker et al. 1997).

E282K is a KCNJ11 mutation which prevents the $\mathrm{K}_{\mathrm{ATP}}$ channel surface expression; however, unlike other trafficking mutations this one does not affect protein folding (Taneja et al. 2009). It has been reported that the C-terminus of the SUR1 subunit is required for $\mathrm{K}_{\mathrm{ATP}}$ channel function (Giblin et al. 2002) whilst others have shown it to be required for membrane expression (Sharma et al. 1999).

Abnormalities in regulation The SUR1 protein acts as conductance regulator of Kir6.2, and both subunits are sensitive to changes in nucleotides such as ATP, ADP, GTP and GDP. ATP-induced inhibition of Kir6.2 is countered by the activation of ADP at SUR1. The T1139M and R1215Q mutations in the ABCC 8 gene cause loss of ADP-dependent gating properties of the channel and result in constitutive inhibition of $\mathrm{K}_{\mathrm{ATP}}$ channels by ATP (Dunne et al. 2004). The R1420C mutation is located in SUR1-NBD2, and results of mutational studies have indicated that it reduces the affinity of NBD2 for ATP and ADP (Matsuo et al. 2000).

Dominant $A B C C 8 / K C N J 11$ channel mutations The identification of a single-dominant ABCC 8 mutation causing $\mathrm{CHI}$ was identified by Huopio and colleagues.

Published by Bioscientifica Ltd 
E1506K is a dominant heterozygous mutation, which changes the amino acid at position 1506 from glutamic acid (E) to lysine (K), and caused $\mathrm{CHI}$ in seven related patients (Huopio et al. 2000). The functional consequences of the E1506K mutant were determined using a Xenopus laevis oocytes expression system, and studied using electrophysiological techniques. The cells were investigated under metabolic inhibition using NaAzide, which is known to stimulate $\mathrm{K}_{\mathrm{ATP}}$ channels in intact cells (Trapp \& Ashcroft 2000). The results indicate that when E1507K is expressed alone it is not responsive to metabolic inhibition, but with the addition of diazoxide it elicited a small current. This indicates that, unlike recessive $A B C C 8$ mutations, the E1506K mutant SUR1 subunit could form $\mathrm{K}_{\mathrm{ATP}}$ channels with Kir6.2 which can be activated by diazoxide. The mutation is distal to the Walker B motif, which a highly conserved region known to be activated by nucleotides. Hence it is likely that the mutation prevents $\mathrm{Mg}^{2+}$ binding to the SUR1 Walker B motif, thereby impairing the $\mathrm{Mg}^{2+}$ binding interactions with SUR1 (Huopio et al. 2000).

The most significant difference between dominant and recessive mutations is diazoxide-responsiveness (MacMullen et al. 2011). Unlike patients carrying recessive mutations, patients with dominant mutations are able to maintain normoglycaemia with diazoxide and regular feeds. This is consistent with the functional analysis of dominant mutations which displays normal channel assembly and trafficking to the plasma membrane, whereby the normal allele confers partial channel response to increased ATP and diazoxide, thus eliminating the need for a pancreatectomy. This is in stark contrast to recessive $\mathrm{CHI}$ where a near-total pancreatectomy is the likely outcome for most patients (Shilyansky et al. 1997, Otonkoski et al. 2006).

The phenotype associated with dominant ABCC8/ KCNJ11 mutations is also quite varied, ranging from asymptomatic to persistent $\mathrm{HH}$ in childhood (Kapoor et al. 2011). For adult mutation carriers this may be a cause of dominantly inherited early-onset diabetes.

\section{Dominant mutation carriers developing dia-}

betes A prominent feature observed in some dominant mutation carriers is their tendency to develop diabetes mellitus (DM). However, not all cohorts have reported DM, despite family members experiencing hypoglycaemia continuing into adulthood and beyond the age of 60 (Thornton et al. 2003). The proposed mechanism for development of DM has been attributed to $\beta$-cell apoptosis mediated via enhanced $\beta$-cell depolarisation, resulting in increased $\mathrm{Ca}^{2+}$ entry into the cell (Huopio et al. 2000). Hence, the use of diazoxide may protect $\beta$-cells by reducing $\mathrm{Ca}^{2+}$ influx by delaying onset of apoptosis or postpone development of DM. $\beta$-cell apoptosis or the development of DM has not been observed in SUR1 knockout (KO) mice or Kir6.2 KO mice. This indicates that there are $\mathrm{K}_{\mathrm{ATP}}$ channel-independent pathways involved in the regulation of insulin secretion (Pinney et al. 2008).

\section{Dominant $A B C C 8 / K C N J 11$ mutations with medically unresponsive diffuse disease Results of} several studies have indicated the presence of dominant inactivation of mutations in $A B C C 8$ and $K C N J 11$ which are medically unresponsive. In one study 12 novel missense mutations from 15 families were identified (MacMullen et al. 2011). Most required a pancreatectomy (15/17). The patients were large for gestational age, and the median age during presentation was closer to that of recessive patients, indicating a more severe form of CHI. The diazoxideunresponsive mutations have been located in NBD2, an area where many of the known diazoxide-responsive mutations have been found. This indicates that the clinical effects of dominant mutations cannot be distinguished by location alone (MacMullen et al. 2011).

It has been largely assumed that dominant $A B C C 8 / K C N J 11$ mutations which cause $\mathrm{CHI}$ are mainly diazoxide-responsive, due to the availability of 'spare channels' made entirely of WT $\mathrm{K}_{\mathrm{ATP}}$ channel subunits. However the 'spare' channel theory is not sufficient to explain the mechanism by which dominant mutations cause severe medically unresponsive CHI.

Paternal mutations in $A B C C 8 / K C N J 11$ causing diffuse disease There are two histological forms of CHI: focal CHI (FCHI) and diffuse CHI (DCHI). The focal form occurs when abnormal pancreatic $\beta$-cells are localised to a single location in the pancreas, resulting in a focal lesion. The diffuse form occurs when all the cells in the pancreas are abnormal in size, and have hypertrophied insulin cells (De Lonlay et al. 1997).

Patients who have a single paternally inherited recessive mutation in the ABCC8 or KCNJ11 gene could have a focal form of CHI, which accounts for $30-40 \%$ of all cases (De Lonlay et al. 1997). However, there are now clinical descriptions of heterozygous paternal mutations causing DCHI and atypical CHI (Chandran et al. 2013). It may be the case that paternal mutations causing DCHI act via a different mechanism from recessive mutations, which generally cause DCHI that is unresponsive to diazoxide. There is also the possibility of a second mutation in the maternal allele, which was not detected by the initial genetic analysis; alternatively there could be a mutation in a non- $A B C C 8$ non-KCNJ11 gene.

Published by Bioscientifica Ltd 
The other known genetic causes of $\mathrm{CHI}$ have so far been identified in seven genes involved in $\beta$-cell dysregulation and inappropriate insulin release (Fig. 2).

\section{Metabolopathies}

The GLUD1 gene: hyperinsulinism/hyperammonaemia syndrome Glutamate is a key compound involved in amino-acid-induced modulation of insulin secretion. Dietary proteins are metabolised to amino acids, which serve as alternative metabolic fuel source in the absence of glucose. Glutamate is degraded by transamination to form $\alpha$-ketoglutarate (and ammonia in the liver and kidney) and enters the TCA cycle to promote ATP and insulin exocytosis.

The glutamate dehydrogenase (GDH) enzyme regulates the entrance of glutamate into the TCA cycle and catalyses the glutaminolysis reaction. Leucine is thought to bind to the GDH catalytic site and promote enzyme action. Two additional sites on GDH also exist: the allosteric inhibitory site which binds GTP and ATP and an ADP-binding activator domain. These sites are thought to regulate the rate of glutaminolysis ( $\mathrm{Li}$ et al. 2003). The GLUD1 gene encodes GDH, and GLUD1activating mutations are the next most genetically prevalent cause of CHI after $A B C C 8 / K C N J 11$ (Li et al. 2003). Mutations in the GLUD1 gene appear to affect GDH's allosteric binding site. These mutations are found in exons 11 and 12 and have been reported to account for more than half of the cases in a cohort of 48 unrelated GDH-CHI patients (Stanley et al. 2000). However, mutations have also been identified in exons 6 and 7 of the catalytic domains, causing normal GDH activity but diminished GTP-sensitivity (Santer et al. 2001).

The majority of GLUD1 mutations occur de novo, but some are due to autosomal inheritance in a dominant fashion (Weinzimer et al. 1997, Stanley et al. 1998). GDH-CHI is also referred to as the hyperinsulinism/ hyperammonaemia (HI/HA) syndrome due to fasting or recurrent postprandial $\mathrm{HH}$ coupled with elevated serum ammonia. The HH link to leucine-sensitivity was initially established by Cochrane et al. (1956) who reported on three related patients experiencing hypoglycaemia on leucine ingestion.

Moreover, elevated levels of plasma glutamine are associated with other hyperammonaemic conditions such as Reye's syndrome, but in the case of GDH (HI/HA)-CHI, this is absent (Weinzimer et al. 1997). All other amino acids in these patients appear within the normal ranges. Initially, the HA was proposed to arise from the liver, but

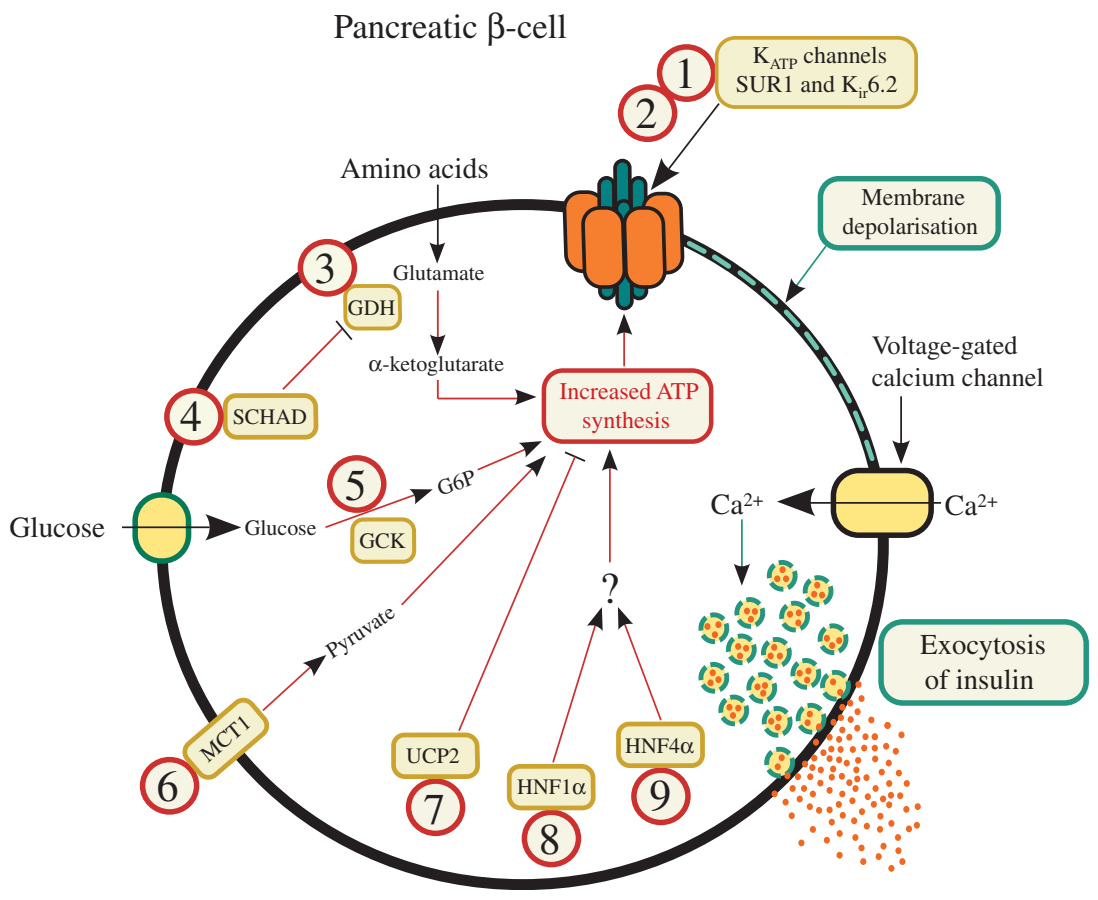

Figure 2

Known genetic mechanisms of $\mathrm{CHI}$. 
was later discovered to be due to renal ammoniagenesis (Treberg et al. 2010). HI/HA-CHI patients are diazoxideresponsive but also require a diet low in protein.

The SCHAD gene: protein-sensitive CHI The $S C H A D$ (or $H A D H$ ) gene encodes the mitochondrial enzyme, short chain 3-hydroxyacyl-CoA dehydrogenase (SCHAD). This enzyme is crucial for $\beta$-oxidation of fatty acids which act as the alternative source of fuel during fasting. The process of $\beta$-oxidation produces acetyl-CoA, but in the absence of carbohydrates, the acetyl-CoA cannot be recycled via the TCA cycle and its accumulation activates ketogenesis. In the penultimate step of $\beta$-oxidation, SCHAD catalyses the oxidation of 3-hydroxyacyl-CoA to 3-ketoacyl-CoA. The transcription factor FOXA2 regulates SCHAD and is essential for $\beta$-cell function and differentiation. Results of studies of $\beta$-cell-specific Foxa2 mice null have revealed a threefold reduction in Schad expression that also appears to exhibit HH (Sund et al. 2001).

SCHAD-CHI is caused by inactivating mutations in the SCHAD gene and is inherited in an autosomal recessive manner. Until recently, the role of SCHAD in CHI was unknown. Results of phenotyping of Hadh-null mice led to the identification of the close relationship between the SCHAD and the GDH enzyme (Li et al. 2010, Heslegrave et al. 2012). SCHAD appears to be a negative regulator of insulin secretion and in SCHAD-CHI, SCHAD loses its inhibitory action on GDH (Li et al. 2010, Heslegrave et al. 2012). Most patients affected are from consanguineous families and are diazoxide-responsive.

To date, ten patients have been identified as having SCHAD-CHI, presenting with varying symptoms from mild late-onset hypoglycaemia to severe neonatal hypoglycaemia. Though HI/HA and SCHAD-CHI patients have similar leucine-sensitive features (Heslegrave et al. 2012), SCHAD-CHI do not present with HA.

The GCK gene: GCK-CHI The GCK gene is conserved amongst different species. Two tissue-specific promoter regions of exon 1 exist, with one specific for the liver and the other for the pancreatic $\beta$-cells. Though these two promoters give rise to different molecules, the two isoforms remain functionally similar.

$G C K$, which encodes the GCK enzyme, is particularly central to the glycolytic pathway and is referred to as the 'glucose sensor'. Its key role is to catalyse the phosphorylation of carbon- 6 on glucose giving rise to glucose-6phosphate (G6P). This in turn is metabolised further and activates insulin release via the regulation by $\mathrm{K}_{\mathrm{ATP}}$ and calcium channels. The rate of phosphorylation of glucose in the $\beta$-cells is dependent on the physiological glucose concentration and thus regulates insulin secretion accordingly. These features include a low affinity for glucose molecules and the absence of inhibition by G6P.

Currently, heterozygous gain-of-function $G C K$ mutations (which are inherited in an autosomal-dominant manner) are known to cause CHI. However, to date there is no support for an increase in GCK expression causing CHI. So far 15 mutations of GCK-CHI have been identified in various sites of the enzyme, including the allosteric domain (A456V, V455M, T65I, G68V, V91L, E422K, V389L, T103S, W99R, W99L, S64Y, V452L, ins454A, M197I and Y214C; Matschinsky 2002). GCK$\mathrm{CHI}$ patients have a higher affinity for glucose and lower threshold for glucose-stimulated insulin secretion (GSIS). CHI caused by GCK mutations accounts for around $7 \%$ of medically responsive $\mathrm{HH}$ and is mainly diazoxide-responsive, although unresponsive forms have also been described. Clinical presentation of GCK-CHI can vary from postprandial hypoglycaemia to mild fasting hypoglycaemia or even seizures.

The SLC16A1 gene: exercise-induced-CHI During glycolytic metabolism, glucose gives rise to pyruvate which is either converted to lactate (during anaerobic exercise) or enters the TCA cycle to produce reducing equivalents for ATP synthesis. The pancreatic $\beta$-cells carefully control the metabolic demand to ensure that blood glucose levels remain within a tight and narrow range. Hence, insulin release requires effective stimulation when glucose concentrations are high and is required switch off just as effectively during states of hypoglycaemia.

These glucose-mediated features which promote insulin release include expression of the glucose-sensing genes such as GLUT2 and GCK, which together enable degradation of glucose as blood sugar levels rise. In addition, by directing glycolysis-derived pyruvate to the mitochondrial TCA cycle, the new pathway diverts insulin secretion by glucose-independent means (Sekine et al. 1994). This speculation was confirmed by the finding of very low lactate dehydrogenase A expression in pancreatic $\beta$-cells as well as slow transport of lactate into the cells (Sekine et al. 1994).

The SLC16A1 gene encodes the monocarboxylate transporter subtype 1 (MCT1). Generally, MCT1 expression is either low or undetectable in $\beta$-cells. SLC16A1 genetic defects are gain-of-function mutations and promote increased $\beta$-cell MCT1 expression which is otherwise transcriptionally silenced. The transporter is therefore thought to allow circulating pyruvate to enter

Published by Bioscientifica Ltd. 
the $\beta$-cells and fuel the TCA cycle, and thus inappropriately promote insulin secretion. However, the genotype-phenotype link between MCT1 and CHI was confirmed only after mice overexpressing Mct1 in $\beta$-cells were generated (Pullen et al. 2012).

SLC16A1 mutations are also referred to as exerciseinduced-CHI and characteristically induce $\mathrm{HH}$ after strenuous exercise or during a pyruvate load (Otonkoski et al. 2003). HH is inherited in an autosomaldominant manner, and mutations have been identified in the regulatory regions of SLC16A1 (Otonkoski et al. 2003). Patients are diazoxide-responsive and are advised to avoid strenuous exercise.

The HNFs Transcription factors are formed by a DNAbinding domain specific for a short sequence of DNA and a domain that influences the transcription of genes by activators or repressors. HNFs are expressed in the pancreas and are involved in pancreatic development, $\beta$-cell mass and insulin release.

The HNF4A gene: nuclear transcription factor 1 ; $\mathrm{CHI}$ to maturity-onset diabetes of youth 1 switch $H N F 4 A$ encodes the HNF4a protein. The gene has two promoter regions, P1 and P2, which have tissue-specific expression. The P1 promoter gives rise to hepatic-tissue-derived $H N F 4 A$ isoforms, whereas the P2 transcription is most abundant in the pancreatic $\beta$-cells and important in the regulation of GSIS (Miura et al. 2006).

Heterozygous dominant inactivating mutations of HNF4A cause CHI and then eventually maturity-onset diabetes of youth (MODY1: an autosomal dominant disorder; Pearson et al. 2007). Mice lacking $\beta$-cell Hnf4a have been reported to have a reduction in the expression of Kcjn11 (Gupta et al. 2005). However, this finding has not been reproduced in other Hnf4a mice models (Miura et al. 2006), hence the mechanism of HNF4a action is still unknown.

Further speculation regarding the switch from hypoglycaemia to hyperglycaemia includes the notion that hypersecretion of insulin causes exertion on the $\beta$-cells (Glaser 2007). Other possible mechanisms of HNF4a-CHI may be the loss of interactions between HNF4a and other nuclear factors such as peroxisome proliferator-activated receptor a (PPARa).

Exposure to low fatty acid concentrations has been shown to promote a loss of GSIS in islets, which is reversible on fatty acid replacement (Stein et al. 1996). Long-term exposure to fatty acids causes a rise in the level of transcription factors such as PPAR- $\alpha$. It has been suggested that PPAR- $\alpha$ directs fatty acids to the $\beta$-oxidation pathway and promotes an elevation of insulin secretion during hypoglycaemia (Sugden \& Holness 2004). This hypothesis is supported by the reduction in PPAR- $\alpha$ expression in $\beta$-cell Hnf4a-null mice (Gupta et al. 2005). Moreover, Ppara-null mice have also been reported to develop fasted HH (Gremlich et al. 2005).

In HNF4a-CHI patients, severity of fasting hypoglycaemia ranges from transient to persistent, requiring medical therapy. However, the majority of cases appear to be diazoxide-responsive and $\mathrm{HH}$ characteristically improves with age. However, the mechanism for this mutation still remains unknown.

The HNF1A gene: nuclear transcription factor 2; $\mathrm{CHI}$ to MODY3 switch HNF1A is a gene that encodes the protein HNF1- $\alpha$. It is found highly expressed in the liver as well as the pancreatic acinar- and $\beta$-cells. HNF1- $\alpha$ is thought to be involved in the expression of several tissue-specific genes. Loss-of-function of HNF1- $\alpha$ has been identified in macrosomic births presenting with diazoxide-responsive CHI. However, in later life, patients appear to switch from hypoglycaemia to MODY3. Though the loss of HNF1- $\alpha$ function does inevitably cause insulin dysregulation as shown using Hnf1a-null mice (Pontoglio et al. 1998), the exact mechanism is unknown.

Moreover, the pancreatic $H N F 4 A$ P2 promoter appears to regulate HNF1- $\alpha$ because binding sites for this exist on its P2 region. Furthermore, deletion of a HNF4- $\alpha$ binding site on the HNF1A promoter abolishes the promoters activity (Kuo et al. 1992). The results of these studies have highlighted the importance of these interlinked transcription factors and the involvement they have in causing this dual phenotype of hypoglycaemia to hyperglycaemia during development. However, further work is still required to elucidate the exact mechanism of the dysregulation that causes HH and then MODY.

The UCP2 gene UCP2 is a mitochondrial carrier and is encoded by the UCP2 gene found in the pancreatic $\alpha$ - and $\beta$-cells. UCP2 contains six TMDs and one nucleotide binding site, which dimerises and forms a proton channel. UCP2 is thought to produce proton leaks across the inner mitochondrial membrane, which uncouples oxidative phosphorylation from ATP synthesis (Zhang et al. 2001).

Rats that fasted for $24 \mathrm{~h}$ had an $82 \%$ increase in islet Ucp2 expression (Gremlich et al. 2005). However, UCP2 has been implicated as a negative regulator of insulin secretion because it reduces the formation of ATP from glucose. PPAR- $\alpha$ is also known to upregulate islet UCP2 expression in hypoglycaemic states, such as fasting.

Published by Bioscientifica Ltd. 
Under normal conditions, UCP2 reduces ATP synthesis and thus suppresses GSIS even in the presence of enhanced fatty acid oxidation (Tordjman et al. 2002).

Ucp2-null mice have been shown to display HH with an increase in islet ATP production (Zhang et al. 2001). This led to the discovery of an inactivating UCP2 mutation in a group of $\mathrm{CHI}$ patients who were all negative for the other known genetic causes of $\mathrm{HH}$ (Gonzalez-Barroso et al. 2008). However, the results of this study indicated that UCP2 indirectly inhibited ATP production. It has also been proposed that UCP2 acts to reduce the formation of mitochondrial reactive oxygen species and thus attenuate GSIS (Emre et al. 2007). In contrast, findings of studies using Ucp2 transgenic mice as well as in vitro studies using $\beta$-cell lines did not support the hypothesis that a rise in UCP2 per se decreases insulin secretion. Hence, a debate still exists as to whether UCP2 mutations promote hypoglycaemia.

UCP2 loss-of-function appears to be inherited in an autosomal-dominant fashion and patients described so far are reportedly diazoxide-responsive. The mutation was originally identified in two unrelated patients with no known genetic cause of CHI (Gonzalez-Barroso et al. 2008). However, the mutation may cause transient or mild fasting $\mathrm{CHI}$ since the patients described are less than 6 years old.

\section{Histological characterisation of $\mathrm{CHI}$}

Currently, there are three histological forms of CHI: FCHI, DCHI and atypical. FCHI occurs when the abnormal pancreatic $\beta$-cells are localised to a single specific location in the pancreas. The DCHI form occurs when all the islet cells in the pancreas are abnormal (Goossens et al. 1989, Sempoux et al. 2004). The clinical presentation of FCHI and DCHI appear to be similar, although their molecular mechanisms are quite different. In most cases DCHI is inherited in an autosomal recessive manner, whereas FCHI is sporadic (Huopio et al. 2000, Henquin et al. 2011). However, where the cases are difficult to histologically categorise these are classified as atypical forms. Generally, atypical forms are thought to be due to morphological mosaicism in a portion of the pancreas.

\section{Molecular basis of FCHI}

Focal lesions are the result of two unique events, first the inheritance of a paternally inherited $A B C C 8$ or KCNJ11 mutation at $11 \mathrm{p} 15.1$, and secondly the loss of the corresponding maternal allele within the focal lesion.
This causes an imbalance in the expression of the imprinted genes such as the maternally expressed tumour suppressor gene $H 19$ and $C D K N 1 C$, and the paternally expressed growth factor IGF2 at 11p15.5 (Sempoux et al. 2011) leading to $\beta$-cell hyperplasia. This loss of heterozygosity for the maternal $11 \mathrm{p}$ region causes a disruption in the expression of genes in a single pancreatic $\beta$-cell clone, which leads to deregulated insulin secretion from the resulting focal islet cell adenomatous hyperplasia with abnormally large nuclei.

A duplication of the paternal allele located on chromosome 11 has also been found in cases of FCHI (Damaj et al. 2008). Outside the lesion, normal endocrine tissue with small nuclei exists. These cells appear to have less cytoplasm and diminished proinsulin production (Rahier et al. 1984, 2000, Goossens et al. 1989, Sempoux et al. 1998).

Patients who have a heterozygous paternally inherited mutation in the $A B C C 8$ or $K C N J 11$ gene could have FCHI, which accounts for $30-40 \%$ of all CHI cases (Rahier et al. 1998). FCHI is confirmed by a fluorine- 18 dihydroxyphenylalanine-positron emission tomography scan, which can show the presence of a focal lesion and determine its location with diagnostic accuracy (Otonkoski et al. 2006). Surgery is needed to remove the focal lesion(s), which usually cure the patients of the hypoglycaemia.

\section{Molecular basis of DCHI}

Patients with a homozygous recessive or a compound heterozygote mutation in their ABCC8 or KCNJ11 genes present with DCHI. These patients are usually medically unresponsive, and this histological form accounts for $60-70 \%$ of all CHI cases. In the DCHI state all the pancreatic $\beta$-cells are affected (Rahier et al. 2000). Most islets throughout the entire pancreas are affected with the presence of large hyperchromatic nuclei (Rahier et al. 1984, 2000, Goossens et al. 1989, Sempoux et al. 1998, 2004). The vast majority of patients in this category undergo a 'near total pancreatectomy', which means more than $95 \%$ of the pancreas is removed through surgery, causing diabetes and exocrine insufficiency.

\section{Molecular basis of atypical $\mathrm{CHI}$}

Histologically, atypical forms of $\mathrm{CHI}$ are categorised when the pancreatic morphology does not fit into the FCHI or DCHI types and are a mosaic pattern of the two (Hussain et al. 2008, Sempoux et al. 2011). The islets can be either enlarged or shrunken. Some cases have been cured with

Published by Bioscientifica Ltd. 
a lesionectomy, whilst others also required medical management. However, to date only one patient has been described with a ABCC8 nonsense mutation (Q54X) causing this histological form of CHI (Hussain et al. 2008). Results of studies have indicated that the heterogeneous expression of $\beta$-cells hexokinase 1 in the atypical $\mathrm{CHI}$ may be causing the abnormal insulin release (Henquin et al. 2013, Shi et al. 2015).

\section{Conclusion}

$\mathrm{CHI}$ is a complex heterogeneous condition which leads to unregulated insulin secretion causing $\mathrm{HH}$. The molecular basis of $\mathrm{CHI}$ involves perturbations in the key genes involved in controlling insulin secretion from pancreatic $\beta$-cells. Interestingly the molecular basis of $\mathrm{CHI}$ is only known in about $50 \%$ of patients so far, indicating that there are as yet unidentified mechanisms involved in the regulation of insulin secretion. Understanding these novel mechanisms will provide fundamental new insights into the function of the pancreatic $\beta$-cell.

\section{Declaration of interest}

The authors declare that there is no conflict of interest that could be perceived as prejudicing the impartiality of the review.

\section{Funding}

This review did not receive any specific grant from any funding agency in the public, commercial or not-for-profit sector.

\section{References}

Aynsley-Green A, Hussain K, Hall J, Saudubray JM, Nihoul-Fekete C, De LonlayDebeney P, Brunelle F, Otonkoski T, Thornton P \& Lindley KJ 2000 Practical management of hyperinsulinism in infancy. Archives of Disease in Childhood. Fetal and Neonatal Edition 82 F98-F107. (doi:10.1136/fn.82.2.F98)

Bruining GJ 1990 Recent advances in hyperinsulinism and the pathogenesis of diabetes mellitus. Current Opinion in Pediatrics 2 758-765. (doi:10.1097/00008480-199008000-00024)

Chandran S, Peng FY, Rajadurai VS, Lu YT, Chang KT, Flanagan SE, Ellard S \& Hussain K 2013 Paternally inherited ABCC8 mutation causing diffuse congenital hyperinsulinism. Endocrinology Diabetes \& Metabolism Case Reports 2013 130041. (doi:10.1530/EDM-13-0041)

Cochrane WA, Payne WW, Simpkiss MJ \& Woolf LI 1956 Familial hypoglycemia precipitated by amino acids. Journal of Clinical Investigation 35 411-422. (doi:10.1172/JCI103292)

Crane A \& Aguilar-Bryan L 2004 Assembly, maturation, and turnover of $\mathrm{K}_{\mathrm{ATP}}$ channel subunits. Journal of Biological Chemistry 279 9080-9090. (doi:10.1074/jbc.M311079200)

Damaj L, le Lorch M, Verkarre V, Werl C, Hubert L, Nihoul-Fekete C, Aigrain Y, de Keyzer Y, Romana SP, Bellanne-Chantelot C et al. 2008 Chromosome 11p15 paternal isodisomy in focal forms of neonatal hyperinsulinism. Journal of Clinical Endocrinology and Metabolism 93 4941-4947. (doi:10.1210/jc.2008-0673)
De Lonlay P, Fournet JC, Rahier J, Gross-Morand MS, Poggi-Travert F, Foussier V, Bonnefont JP, Brusset MC, Brunelle F, Robert JJ et al. 1997 Somatic deletion of the imprinted 11 p15 region in sporadic persistent hyperinsulinemic hypoglycemia of infancy is specific of focal adenomatous hyperplasia and endorses partial pancreatectomy. Journal of Clinical Investigation 100 802-807. (doi:10.1172/JCI119594)

Doupnik CA, Davidson N \& Lester HA 1995 The inward rectifier potassium channel family. Current Opinion in Neurobiology 5 268-277. (doi:10.1016/0959-4388(95)80038-7)

Dunne MJ, Cosgrove KE, Shepherd RM, Aynsley-Green A \& Lindley KJ 2004 Hyperinsulinism in infancy: from basic science to clinical disease. Physiological Reviews 84 239-275. (doi:10.1152/physrev.00022.2003)

Emre Y, Hurtaud C, Karaca M, Nubel T, Zavala F \& Ricquier D 2007 Role of uncoupling protein UCP2 in cell-mediated immunity: how macrophage-mediated insulitis is accelerated in a model of autoimmune diabetes. PNAS 104 19085-19090. (doi:10.1073/pnas.0709557104)

Flanagan SE, Clauin S, Bellanne-Chantelot C, de Lonlay P, Harries LW, Gloyn AL \& Ellard S 2009 Update of mutations in the genes encoding the pancreatic beta-cell $\mathrm{K}_{\mathrm{ATP}}$ channel subunits Kir6.2 (KCNJ11) and sulfonylurea receptor $1(A B C C 8)$ in diabetes mellitus and hyperinsulinism. Human Mutation 30 170-180. (doi:10.1002/humu.20838)

Flanagan SE, Kapoor RR, Mali G, Cody D, Murphy N, Schwahn B, Siahanidou T, Banerjee I, Akcay T, Rubio-Cabezas O et al. 2010 Diazoxide-responsive hyperinsulinemic hypoglycemia caused by HNF4A gene mutations. European Journal of Endocrinology 162 987-992. (doi:10.1530/EJE-09-0861)

Gembal M, Gilon P \& Henquin JC 1992 Evidence that glucose can control insulin release independently from its action on ATP-sensitive $\mathrm{K}^{+}$channels in mouse B cells. Journal of Clinical Investigation 89 1288-1295. (doi:10.1172/JCI115714)

Giblin JP, Quinn K \& Tinker A 2002 The cytoplasmic C-terminus of the sulfonylurea receptor is important for $\mathrm{K}_{\mathrm{ATP}}$ channel function but is not key for complex assembly or trafficking. European Journal of Biochemistry 269 5303-5313. (doi:10.1046/j.1432-1033.2002.03249.x)

Glaser B 2007 Type 2 diabetes: hypoinsulinism, hyperinsulinism, or both? PLoS Medicine 4 e148. (doi:10.1371/journal.pmed.0040148)

Glaser B, Kesavan P, Heyman M, Davis E, Cuesta A, Buchs A, Stanley CA, Thornton PS, Permutt MA, Matschinsky FM et al. 1998 Familial hyperinsulinism caused by an activating glucokinase mutation. New England Journal of Medicine 338 226-230. (doi:10.1056/ NEJM199801223380404)

Gonzalez-Barroso MM, Giurgea I, Bouillaud F, Anedda A, BellanneChantelot C, Hubert L, de Keyzer Y, de Lonlay P \& Ricquier D 2008 Mutations in UCP2 in congenital hyperinsulinism reveal a role for regulation of insulin secretion. PLOS ONE 3 9. (doi:10.1371/journal. pone.0003850)

Goossens A, Gepts W, Saudubray JM, Bonnefont JP, Nihoul-Fekete, Heitz PU \& Klöppel G 1989 Diffuse and focal nesidioblastosis. A clinicopathological study of 24 patients with persistent neonatal hyperinsulinemic hypoglycemia. American Journal of Surgical Pathology 3 766-775. (doi:10.1097/00000478-198909000-00006)

Gremlich S, Nolan C, Roduit R, Burcelin R, Peyot ML, Delghingaro-Augusto V, Desvergne B, Michalik L, Prentki M \& Wahli W 2005 Pancreatic islet adaptation to fasting is dependent on peroxisome proliferator-activated receptor $\alpha$ transcriptional up-regulation of fatty acid oxidation. Endocrinology 146 375-382. (doi:10.1210/en.2004-0667)

Gupta RK, Vatamaniuk MZ, Lee CS, Flaschen RC, Fulmer JT, Matschinsky FM, Duncan SA \& Kaestner KH 2005 The MODY1 gene $H N F-4 \alpha$ regulates selected genes involved in insulin secretion. Journal of Clinical Investigation 115 1006-1015. (doi:10.1172/JCI200522365)

Henquin JC, Nenquin M, Sempoux C, Guiot Y, Bellanne-Chantelot C, Otonkoski T, de Lonlay P, Nihoul-Fekete C \& Rahier J 2011 In vitro insulin secretion by pancreatic tissue from infants with diazoxideresistant congenital hyperinsulinism deviates from model predictions. Journal of Clinical Investigation 121 3932-3942. (doi:10.1172/JCI58400) 
Henquin JC, Sempoux C, Marchandise J, Godecharles S, Guiot Y, Nenquin M \& Rahier J 2013 Congenital hyperinsulinism caused by hexokinase I expression or glucokinase-activating mutation in a subset of $\beta$-cells. Diabetes 62 1689-1696. (doi:10.2337/db12-1414)

Heslegrave AJ, Kapoor RR, Eaton S, Chadefaux B, Akcay T, Simsek E, Flanagan SE, Ellard S \& Hussain K 2012 Leucine-sensitive hyperinsulinaemic hypoglycaemia in patients with loss of function mutations in 3-hydroxyacyl-CoA dehydrogenase. Orphanet Journal of Rare Diseases 7 25. (doi:10.1186/1750-1172-7-25)

Huopio H, Reimann F, Ashfield R, Komulainen J, Lenko H-L, Rahier J, Vauhkonen I, Kere J, Laakso M, Ashcroft F et al. 2000 Dominantly inherited hyperinsulinism caused by a mutation in the sulfonylurea receptor type 1. Journal of Clinical Investigation 106 897-906. (doi:10.1172/JCI9804)

Hussain K, Flanagan SE, Smith VV, Ashworth M, Day M, Pierro A \& Ellard S 2008 An ABCC8 gene mutation and mosaic uniparental isodisomy resulting in atypical diffuse congenital hyperinsulinism. Diabetes $\mathbf{5 7}$ 259-263. (doi:10.2337/db07-0998)

Inagaki N, Gonoi T, Clement JP, Namba N, Inazawa J, Gonzalez G, AguilarBryan L, Seino S \& Bryan J 1995 Reconstitution of $I_{\text {KATP: }}$ an inward rectifier subunit plus the sulfonylurea receptor. Science 270 1166-1170. (doi:10.1126/science.270.5239.1166)

Kapoor RR, Flanagan SE, James CT, McKiernan J, Thomas AM, Harmer SC, Shield JP, Tinker A, Ellard S \& Hussain K 2011 Hyperinsulinaemic hypoglycaemia and diabetes mellitus due to dominant ABCC8/ KCNJ11 mutations. Diabetologia 54 2575-2583. (doi:10.1007/s00125011-2207-4)

Kapoor RR, Flanagan SE, Arya VB, Shield JP, Ellard S \& Hussain K 2013 Clinical and molecular characterisation of 300 patients with congenital hyperinsulinism. European Journal of Endocrinology 168 557-564. (doi:10.1530/EJE-12-0673)

Komatsu M, Schermerhorn T, Aizawa T \& Sharp GW 1995 Glucose stimulation of insulin release in the absence of extracellular $\mathrm{Ca}^{2+}$ and in the absence of any increase in intracellular $\mathrm{Ca}^{2+}$ in rat pancreatic islets. PNAS 92 10728-10732. (doi:10.1073/pnas.92.23.10728)

Kuo CJ, Conley PB, Chen L, Sladek FM, Darnell JE Jr \& Crabtree GR 1992 A transcriptional hierarchy involved in mammalian cell-type specification. Nature 355 457-461. (doi:10.1038/355457a0)

Li C, Najafi H, Daikhin Y, Nissim IB, Collins HW, Yudkoff M, Matschinsky FM \& Stanley CA 2003 Regulation of leucine-stimulated insulin secretion and glutamine metabolism in isolated rat islets. Journal of Biological Chemistry 278 2853-2858. (doi:10.1074/jbc. M210577200)

Li C, Chen P, Palladino A, Narayan S, Russell LK, Sayed S, Xiong G, Chen J, Stokes D, Butt YM et al. 2010 Mechanism of hyperinsulinism in short-chain 3-hydroxyacyl-CoA dehydrogenase deficiency involves activation of glutamate dehydrogenase. Journal of Biological Chemistry 285 31806-31818. (doi:10.1074/jbc.M110.123638)

MacMullen CM, Zhou Q, Snider KE, Tewson PH, Becker SA, Aziz AR, Ganguly A, Shyng S-L \& Stanley CA 2011 Diazoxide-unresponsive congenital hyperinsulinism in children with dominant mutations of the $\beta$-cell sulfonylurea receptor SUR1. Diabetes 60 1797-1804. (doi:10.2337/db10-1631)

Matschinsky FM 2002 Regulation of pancreatic $\beta$-cell glucokinase: from basics to therapeutics. Diabetes 51 (Suppl 3) S394-S404. (doi:10.2337/ diabetes.51.2007.S394)

Matsuo M, Trapp S, Tanizawa Y, Kioka N, Amachi T, Oka Y, Ashcroft FM \& Ueda K 2000 Functional analysis of a mutant sulfonylurea receptor, SUR1-R1420C, that is responsible for persistent hyperinsulinemic hypoglycemia of infancy. Journal of Biological Chemistry $\mathbf{2 7 5}$ 41184-41191. (doi:10.1074/jbc.M006503200)

Miura A, Yamagata K, Kakei M, Hatakeyama H, Takahashi N, Fukui K, Nammo T, Yoneda K, Inoue Y, Sladek FM et al. 2006 Hepatocyte nuclear factor- $4 \alpha$ is essential for glucose-stimulated insulin secretion by pancreatic $\beta$-cells. Journal of Biological Chemistry 281 5246-5257. (doi:10.1074/jbc.M507496200)
Nichols CG, Shyng S-L, Nestorowicz A, Glaser B, Clement JP, Gonzalez G, Aguilar-Bryan L, Permutt MA \& Bryan J 1996 Adenosine diphosphate as an intracellular regulator of insulin secretion. Science 272 1785-1787. (doi:10.1126/science.272.5269.1785)

Otonkoski T, Kaminen N, Ustinov J, Lapatto R, Meissner T, Mayatepek E, Kere J \& Sipilä I 2003 Physical exercise-induced hyperinsulinemic hypoglycemia is an autosomal-dominant trait characterized by abnormal pyruvate-induced insulin release. Diabetes 52 199-204. (doi:10.2337/diabetes.52.1.199)

Otonkoski T, Näntö-Salonen K, Seppänen M, Veijola R, Huopio H, Hussain K, Tapanainen P, Eskola O, Parkkola R, Ekström K et al. 2006 Noninvasive diagnosis of focal hyperinsulinism of infancy with $\left[{ }^{18} \mathrm{~F}\right]$-DOPA positron emission tomography. Diabetes 55 13-18. (doi:10.2337/diabetes.55.01. 06.db05-1128)

Pearson ER, Boj SF, Steele AM, Barrett T, Stals K, Shield JP, Ellard S, Ferrer J \& Hattersley AT 2007 Macrosomia and hyperinsulinaemic hypoglycaemia in patients with heterozygous mutations in the HNF4A gene. PLoS Medicine 4 e118 0760-0769. (doi:10.1371/journal.pmed.0040118)

Pinney SE, MacMullen C, Becker S, Lin Y-W, Hanna C, Thornton P, Ganguly A, Shyng S-L \& Stanley CA 2008 Clinical characteristics and biochemical mechanisms of congenital hyperinsulinism associated with dominant $\mathrm{K}_{\mathrm{ATP}}$ channel mutations. Journal of Clinical Investigation 118 2877-2886. (doi:10.1172/JCI35414)

Pontoglio M, Sreenan S, Roe M, Pugh W, Ostrega D, Doyen A, Pick AJ, Baldwin A, Velho G, Froguel P et al. 1998 Defective insulin secretion in hepatocyte nuclear factor $1 \alpha$-deficient mice. Journal of Clinical Investigation 101 2215-2222. (doi:10.1172/JCI2548)

Pullen TJ, Sylow L, Sun G, Halestrap AP, Richter EA \& Rutter GA 2012 Overexpression of monocarboxylate transporter-1 (Slc16a1) in mouse pancreatic $\beta$-cells leads to relative hyperinsulinism during exercise. Diabetes 61 1719-1725. (doi:10.2337/db11-1531)

Rahier J, Falt K, Muntefering H, Becker K, Gepts W \& Falkmer S 1984 The basic structural lesion of persistent neonatal hypoglycaemia with hyperinsulinism: deficiency of pancreatic D cells or hyperactivity of B cells? Diabetologia 26 282-289. (doi:10.1007/BF00283651)

Rahier J, Sempoux C, Fournet JC, Poggi F, Brunelle F, Nihoul-Fekete C, Saudubray JM \& Jaubert F 1998 Partial or near-total pancreatectomy for persistent neonatal hyperinsulinaemic hypoglycaemia: the pathologist's role. Histopathology 32 15-19. (doi:10.1046/j.1365-2559. 1998.00326.x)

Rahier J, Guiot Y \& Sempoux C 2000 Persistent hyperinsulinaemic hypoglycaemia of infancy: a heterogeneous syndrome unrelated to nesidioblastosis. Archives of Disease in Childhood. Fetal and Neonatal Edition 82 F108-F112. (doi:10.1136/fn.82.2.F108)

Saint-Martin C, Arnoux J-B, de Lonlay P \& Bellanné-Chantelot C $2011 \mathrm{~K}_{\mathrm{ATP}}$ channel mutations in congenital hyperinsulinism. Seminars in Pediatric Surgery 20 18-22. (doi:10.1053/j.sempedsurg.2010.10.012)

Santer R, Kinner M, Passarge M, Superti-Furga A, Mayatepek E, Meissner T, Schneppenheim R \& Schaub J 2001 Novel missense mutations outside the allosteric domain of glutamate dehydrogenase are prevalent in European patients with the congenital hyperinsulinism-hyperammonemia syndrome. Human Genetics 108 66-71. (doi:10.1007/ s004390000432)

Sekine N, Cirulli V, Regazzi R, Brown LJ, Gine E, Tamarit-Rodriguez J, Girotti M, Marie S, MacDonald MJ, Wollheim CB et al. 1994 Low lactate dehydrogenase and high mitochondrial glycerol phosphate dehydrogenase in pancreatic $\beta$-cells. Potential role in nutrient sensing. Journal of Biological Chemistry 269 4895-4902.

Sempoux C, Guiot Y, Lefevre A, Nihoul-Fekete C, Jaubert F, Saudubray JM \& Rahier J 1998 Neonatal hyperinsulinemic hypoglycemia: heterogeneity of the syndrome and keys for differential diagnosis. Journal of Clinical Endocrinology and Metabolism 83 1455-1461. (doi:10.1210/jcem.83.5. 4768)

Sempoux C, Guiot Y, Jaubert F \& Rahier J 2004 Focal and diffuse forms of congenital hyperinsulinism: the keys for differential diagnosis. Endocrine Pathology 15 241-246. (doi:10.1385/EP:15:3:241) 
Sempoux C, Capito C, Bellanné-Chantelot C, Verkarre V, de Lonlay P, Aigrain Y, Fekete C, Guiot Y \& Rahier J 2011 Morphological mosaicism of the pancreatic islets: a novel anatomopathological form of persistent hyperinsulinemic hypoglycemia of infancy. Journal of Clinical Endocrinology and Metabolism 96 3785-3793. (doi:10.1210/jc.2010-3032)

Sharma N, Crane A, Clement JP, Gonzalez G, Babenko AP, Bryan J \& Aguilar-Bryan L 1999 The C terminus of SUR1 is required for trafficking of $\mathrm{K}_{\mathrm{ATP}}$ channels. Journal of Biological Chemistry 274 20628-20632. (doi:10.1074/jbc.274.29.20628)

Shi Y, Avatapalle HB, Skae MS, Padidela R, Newbould M, Rigby L, Flanagan SE, Ellard S, Rahier J, Clayton PE et al. 2015 Increased plasma incretin concentrations identifies a subset of patients with persistent congenital hyperinsulinism without $\mathrm{K}_{\mathrm{ATP}}$ channel gene defects. Journal of Pediatrics 166 191-194. (doi:10.1016/j.jpeds.2014.09.019)

Shilyansky J, Fisher S, Cutz E, Perlman K \& Filler RM 1997 Is 95\% pancreatectomy the procedure of choice for treatment of persistent hyperinsulinemic hypoglycemia of the neonate? Journal of Pediatric Surgery 32 342-346. (doi:10.1016/S0022-3468(97)90207-4)

Snider KE, Becker S, Boyajian L, Shyng S-L, MacMullen C, Hughes N, Ganapathy K, Bhatti T, Stanley CA \& Ganguly A 2013 Genotype and phenotype correlations in 417 children with congenital hyperinsulinism. Journal of Clinical Endocrinology \& Metabolism 98 E355-E363. (doi:10.1210/jc.2012-2169)

Stanley CA, Lieu YK, Hsu BY, Burlina AB, Greenberg CR, Hopwood NJ, Perlman K, Rich BH, Zammarchi E \& Poncz M 1998 Hyperinsulinism and hyperammonemia in infants with regulatory mutations of the glutamate dehydrogenase gene. New England Journal of Medicine 338 1352-1357. (doi:10.1056/NEJM199805073381904)

Stanley CA, Fang J, Kutyna K, Hsu BY, Ming JE, Glaser B \& Poncz M 2000 Molecular basis and characterization of the hyperinsulinism/ hyperammonemia syndrome: predominance of mutations in exons 11 and 12 of the glutamate dehydrogenase gene. HI/HA Contributing Investigators. Diabetes 49 667-673. (doi:10.2337/diabetes.49.4.667)

Stein DT, Esser V, Stevenson BE, Lane KE, Whiteside JH, Daniels MB, Chen S \& McGarry JD 1996 Essentiality of circulating fatty acids for glucosestimulated insulin secretion in the fasted rat. Journal of Clinical Investigation 97 2728-2735. (doi:10.1172/JCI118727)

Sugden MC \& Holness MJ 2004 Potential role of peroxisome proliferatoractivated receptor- $\alpha$ in the modulation of glucose-stimulated insulin secretion. Diabetes 53 (Suppl 1) S71-S81. (doi:10.2337/diabetes. 53.2007.S71)

Sund NJ, Vatamaniuk MZ, Casey M, Ang SL, Magnuson MA, Stoffers DA, Matschinsky FM \& Kaestner KH 2001 Tissue-specific deletion of Foxa2 in pancreatic $\beta$ cells results in hyperinsulinemic hypoglycemia. Genes and Development 15 1706-1715. (doi:10.1101/gad.901601)

Taneja TK, Mankouri J, Karnik R, Kannan S, Smith AJ, Munsey T, Christesen HB, Beech DJ \& Sivaprasadarao A 2009 Sar1-GTPasedependent ER exit of $\mathrm{K}_{\mathrm{ATP}}$ channels revealed by a mutation causing congenital hyperinsulinism. Human Molecular Genetics 18 2400-2413. (doi:10.1093/hmg/ddp179)

Thornton PS, MacMullen C, Ganguly A, Ruchelli E, Steinkrauss L, Crane A, Aguilar-Bryan L \& Stanley CA 2003 Clinical and molecular characterization of a dominant form of congenital hyperinsulinism caused by a mutation in the high-affinity sulfonylurea receptor. Diabetes $\mathbf{5 2}$ 2403-2410. (doi:10.2337/diabetes.52.9.2403)

Tordjman K, Standley KN, Bernal-Mizrachi C, Leone TC, Coleman T, Kelly DP $\&$ Semenkovich CF 2002 PPAR $\alpha$ suppresses insulin secretion and induces UCP2 in insulinoma cells. Journal of Lipid Research 43 936-943.

Trapp S \& Ashcroft FM 2000 Direct interaction of Na-azide with the $\mathrm{K}_{\text {ATP }}$ channel. British Journal of Pharmacology 131 1105-1112. (doi:10.1038/ sj.bjp.0703680)

Treberg JR, Clow KA, Greene KA, Brosnan ME \& Brosnan JT 2010 Systemic activation of glutamate dehydrogenase increases renal ammoniagenesis: implications for the hyperinsulinism/hyperammonemia syndrome. American Journal of Physiology. Endocrinology and Metabolism 298 E1219-E1225. (doi:10.1152/ajpendo.00028.2010)

Tucker SJ, Gribble FM, Zhao C, Trapp S \& Ashcroft FM 1997 Truncation of Kir6.2 produces ATP-sensitive $\mathrm{K}^{+}$channels in the absence of the sulphonylurea receptor. Nature 387 179-183. (doi:10.1038/387179a0)

Weinzimer SA, Stanley CA, Berry GT, Yudkoff M, Tuchman M \& Thornton PS 1997 A syndrome of congenital hyperinsulinism and hyperammonemia. Journal of Pediatrics 130 661-664. (doi:10.1016/ S0022-3476(97)70256-7)

Zhang CY, Baffy G, Perret P, Krauss S, Peroni O, Grujic D, Hagen T, VidalPuig AJ, Boss O, Kim YB et al. 2001 Uncoupling protein-2 negatively regulates insulin secretion and is a major link between obesity, $\beta$ cell dysfunction, and type 2 diabetes. Cell 105 745-755. (doi:10.1016/ S0092-8674(01)00378-6)

Received in final form 16 February 2015 Accepted 2 March 2015
(C) 2015 Society for Endocrinology Printed in Great Britain 